sciendo

DOI: 10.2478/sjpna-2019-0017

\title{
RADAR DATA FUSION IN THE STRADAR SYSTEM
}

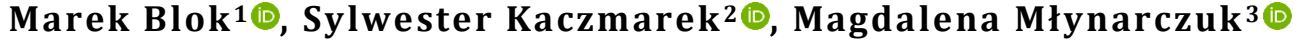 \\ Gdansk University of Technology, Faculty of Electronics, Telecommunications and Informatics, De- \\ partment of Teleinformation Networks, Narutowicza 11/12 Str., 80-233 Gdańsk, Poland, e-mail: \\ mblok@eti.pg.edu.pl,kasyl@eti.pg.edu.pl, magdam@eti.pg.edu.pl; ORCID ID: 10000-0002-8793-1697, \\ 20000-0003-2932-5610, 30000-0002-8509-2914
}

\begin{abstract}
The main task of the Polish Border Guard is protection of the country's border which requires utilization of multimedia surveillance systems automatically gathering, processing and sharing various data. The paper presents such a system developed for the Maritime Division of the Polish Border Guard within the STRADAR project and the problem of fusion of radar data in this system. The system, apart from providing communication means, gathers data from AIS, GPS and radar receivers: ARPA and SCANTER 2001. In the paper the concept of the radar data gathering in STRADAR system is provided with detailed presentation of radar servers, Radar INT modules and a reduplication (fusion) module and the proposition of the algorithm for radar data fusion.
\end{abstract}

\section{Keywords:}

data fusion, navigation, ARPA, SCANTER 2001, reduplication of position data.

Research article

(C) 2019 Marek Blok, Sylwester Kaczmarek, Magdalena Młynarczuk This is an open access article licensed under the Creative Commons Attribution-NonCommercial-NoDerivatives 4.0 license (http://creativecommons.org/licenses/by-nc-nd/4.0/) 


\section{INTRODUCTION}

The STRADAR system is a distributed multi-media surveillance system which was developed based on the KONSOLA project designed as an extension to the Automatic National System of Radar Control for Maritime Areas of Poland (Zautomatyzowany System Radarowego Nadzoru Polskich Obszarów Morskich — ZSRN) [1, 5]. The main limitation of the ZSRN system is that BG mobile units are not connected to the central system $[5,6]$ which have been addressed in KONSOLA and STRADAR systems. The STRADAR project apart from allowing for map data exchange (AIS, radar) provides functionalities for gathering, archiving and providing access to multimedia data such as camera video data, photos, audio data including phone calls, SMS and data files. Hardware and software implementation of the STRADAR system with presentation of acceptance tests performed under the supervision of the gestor, i.e. the Polish Border Guard, are presented in [1, 2].

The STRADAR system gathers and presents on maps radar data from $\mathrm{Au}$ tomatic Radar Plotting Aids (ARPA) on Mobile Units (MUs). If radar data represent the same objects at the same positions, they are integrated based on different sources in MUs and in the Central Server to eliminate redundant objects' data. Currently, the STRADAR is developed to increase the radar data visualization functionalities and services based on particular type of pulse radar manufactured by the Danish company Terma (SCANTER 2001). Integration of radar data obtained from ARPA and SCANTER 2001 sources is an important problem, which needs to be solved in order to ensure the correct performance of radar data visualization.

Complex radar data visualization is compatible with current tendencies in development of border guard advanced surveillance and monitoring. Operations of the Polish National Maritime Safety System (KSBM) are focused on radar functionalities which are designed to the early detection and accurate tracking of ships for the purpose of preventing maritime accidents and pollution of the sea and the coast line [15]. Radars supply reliable ship identification and safety navigation even if the object (target) is untraceable by AIS i.e. has no an Automatic Identification System (AIS) transmitter. Moreover, AIS data have to be treated with some level of distrust, since AIS message depends on the target ship's transmitter configuration and its content sometimes does not coincide with the facts and parts of information may be incorrect due to unintentional or intentional actions [7]. In result, for navigation safety operators of modern Vessel Monitoring System (VMS) mostly concentrate on radar data and AIS receiver is treated as a supplementary data source $[7,9,11]$. 
The goal of this paper is to present the new radar data fusion software dedicated for STRADAR system. In order to accomplish this goal detailed presentation of radar servers, Radar INT modules, a reduplication (fusion) module and the proposition of the algorithm for radar data fusion are provided.

In the next section the main architecture of the STRADAR system and the process of radar data gathering are indicated while in the section 'Fusion of radar data' details of radar data reduplication (fusion) are presented.

\section{THE STRUCTURE OF THE STRADAR SYSTEM}

The overall diagram of the STRADAR system is presented in fig. 1. Currently the system gathers position data from Automatic Identification System (AIS), Global Positioning System (GPS) and Automatic Radar Plotting Aids (ARPA). The STRADAR system collects also video and photos from cameras installed on BG's Mobile Units (MUs) and in Observation Points (OPs), audio data including phone calls received by the BG's officers as well as SMSs and exchanged data files [2, 4]. The system is accessed by the operators from stationary consoles or mobile console on MU. The overall situation awareness can by visualized and monitored on a high resolution multiscreen display (EVP) $[1,2,4]$.

The radar data within the STRADAR system are gathered by MUs and OPs and stored in their local databases. Next MapServers in MUs and OPs transmit position data to the central MapServer in the Central Server (CS) during synchronization between Universal Radio Controllers (URCs) with CS.

The stationary consoles and EVP are connected to the Central Server (SC) directly via the IP network and always obtain map data (radar ARPA, AIS and GPS) from the central database. Mobile consoles are connected to the local MapSerwer on their MU via a local IP network and obtain map data collected in the URC's local database or from CS, if the mobile console operator requests data from the CENTER. Since the acquisition of radar data is based on dispersed sources (URC, OP, CS) there is the problem of their duplication, i.e. CS repeatedly obtains the same or very similar positional data. In this situation, integration of many object tracking radars with AIS and GPS is required. The current functionality of reduplication modules in URC and CS is presented in [7, 8] while the architecture of the software designed for management of position and identification data of vessels and airplanes objects is fully described in [3]. 
The next step in the STRADAR project development is launching a separate radar data reduplication module on Archive Servers (AS) for fusion ARPA radar data (from MUs) and SCANTER 2001 radar data from Video Distribution and Tracking (VDT) server in OPs. In presented diagram (fig. 1) the Server ARPA2IP, the Server VDT and Radar INT modules are responsible for acquisitioning of radar data while the data reduplication function is performed in reduplicator module.

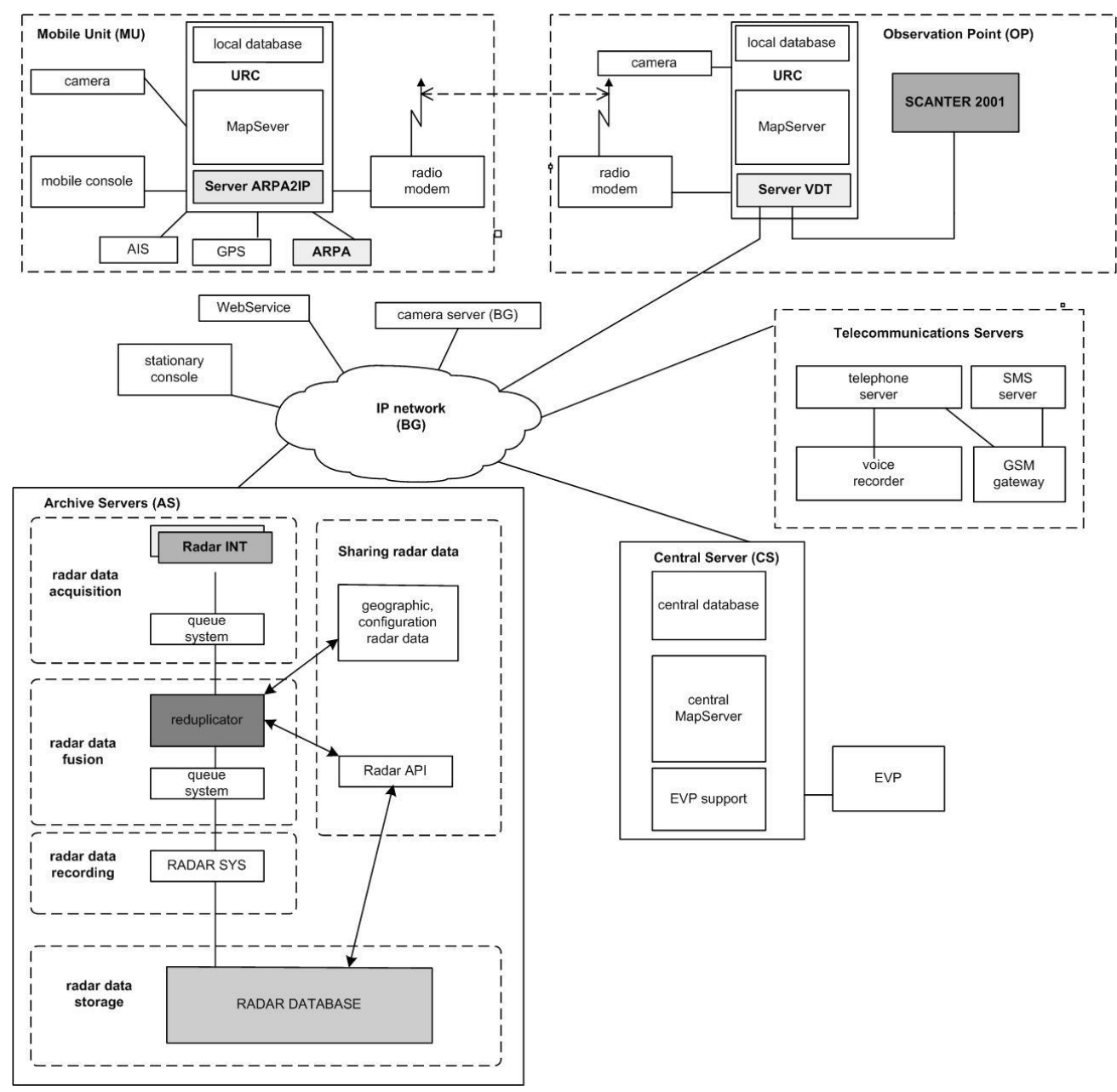

Fig. 1. Diagram of the STRADAR system

At this stage of work, it is assumed that the radar server for ARPA/SCANTER radar data (fig. 1) has two variants: VDT and ARPA2IP and enables transmission of radar data via the IP network. In particular it applies to text data describing detected 
and tracked objects (tracks). In case of radar manufactured by the Danish company Terma SCANTER 2001 a radar server is referred to Server VDT. According to specification VDT [13] server processes raw radar images and makes them available through a TCP/IP network in text format (plot data, track) and binary format (radar video images), as well as enabling the configuration of radar parameters (profiles) [15].

Originally, the VDT server supplies software package 'SCANTER 2001 Control and Tracking Unit' running on a commercial PC. The display unit which contains the function and monitoring control allows the BG operator to work with specific echoes, setting zones with tracking characteristics and tuning some of the main parameters of the radar to optimize the specific profile [15]. The example of visualization for VDT is presented in fig. 2.

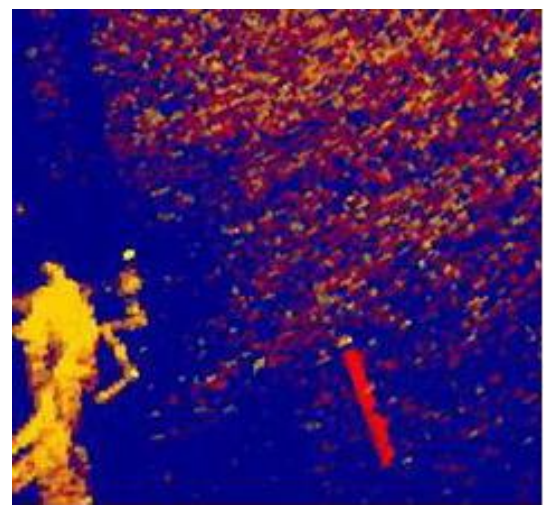

TRAILS

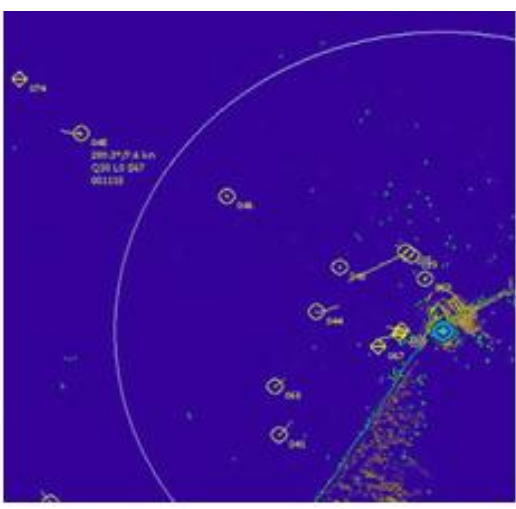

TRACKS

Fig. 2. The example of visualization for VDT (BG's operational materials)

The VDT architecture complies with the concept of the STRADAR system with a set of operators' consoles, the EVP and an Archive Server (AS) connected to an IP network presenting current and archived data taken from many sensors.

In the case of radars compliant with the ARPA protocol, it is necessary to develop an ARPA2IP server as a software launched in the Universal Radio Controller (URC) in the MU. The task of the ARPA2IP server is to receive data from the ARPA radar through the RS-422/RS-232C communication interface and make them available in a raw form compatible with the ARPA message format through the IP network for further processing in the STRADAR system. In addition, the task of the ARPA2IP server is to provide through the IP network the GPS messages in order to allow determination of the ARPA radar position by the STRADAR system (in particular the reduplication module in AS which is particularly important for radars placed on 
Mobile Units, i.e. vehicles and sea-going ships) of the Maritime Border Guard Department.

It should be emphasized that introduction of the ARPA2IP server solution unifies the way radars are handled in the STRADAR system and enables the centralization of archiving, processing and presentation of data coming from both modern radars factory-equipped with an IP server (such as Terma's SCANTER radars) as well as the older generation radars that provide only local access compliant with the ARPA protocol.

The Radar INT module is an element that adapts a custom, characteristic for a particular type of radar interface and IP server protocol message to a uniform message format of the queuing system available in the Advanced Message Queuing Protocol (AMQP). Its role is to receive text positional data from the mentioned radar types and transfer them to the reduplicator module. Another role of the Radar INT module is the integration of text radar data (available as radar messages, named tracks) with data identifying a given radar device, such as, its current position, which is important for radars on Mobile Units, and the time of obtaining a given radar message, which is important for effective radar data processing in the reduplicator module which performs multi-data operation from multiple radars that can refer to the same objects. Due to the assumption in the STRADAR system to support many types of radars, it is possible to implement different types of Radar INT modules corresponding functionally to many types of radar servers. It is assumed that the data received by the Radar INT module will include:

- positional information about the radar unit based on Own Unit Management Protocol (OUMP) [14] for SCANTER 2001 radar or GPS for ARPA radar;

- objects' tracks based on Track Data Interface Protocol (TDIP) for SCANTER 2001 radar [12] or ARPA messages for ARPA radars.

The collected positional data will be transferred to the reduplikator module in AS by queue system with AMQP broker. Received radar data on tracked objects (tracks) will be queued as JSON messages. Each JSON message will contain one or more tracks along with metadata. Incorrect data (e.g., partially received radar messages, messages with an incorrect checksum) will be rejected and will not be placed in the queue.

The reduplicator module in AS is designed to reduplicate data from many sources (radars). Radar messages with metadata in JSON format will be collected from the AMQP queuing system. After the reduplication, the radar data will be sent to the SYS Radar module via the AMQP queue system. It is planned to put data in queues in the form of JSON messages in a uniform format (regardless of the type of 
radar). The structure of the JSON message will contain both information provided by the ARPA radar and Terma SCANTER 2001. The SYS Radar module will be responsible for recording the received data in the SA database.

\section{FUSION OF RADAR DATA}

In this section the algorithm of radar data fusion is proposed. The block diagram of the STRADAR system responsible for acquiring and reduplication radar data in AS is presented in fig. 3. Radar text data are received by Radar INT through the queuing system AMQP and transferred to the reduplicator module. At the beginning, in the initial process, radar data packages are put into preprocessing module.

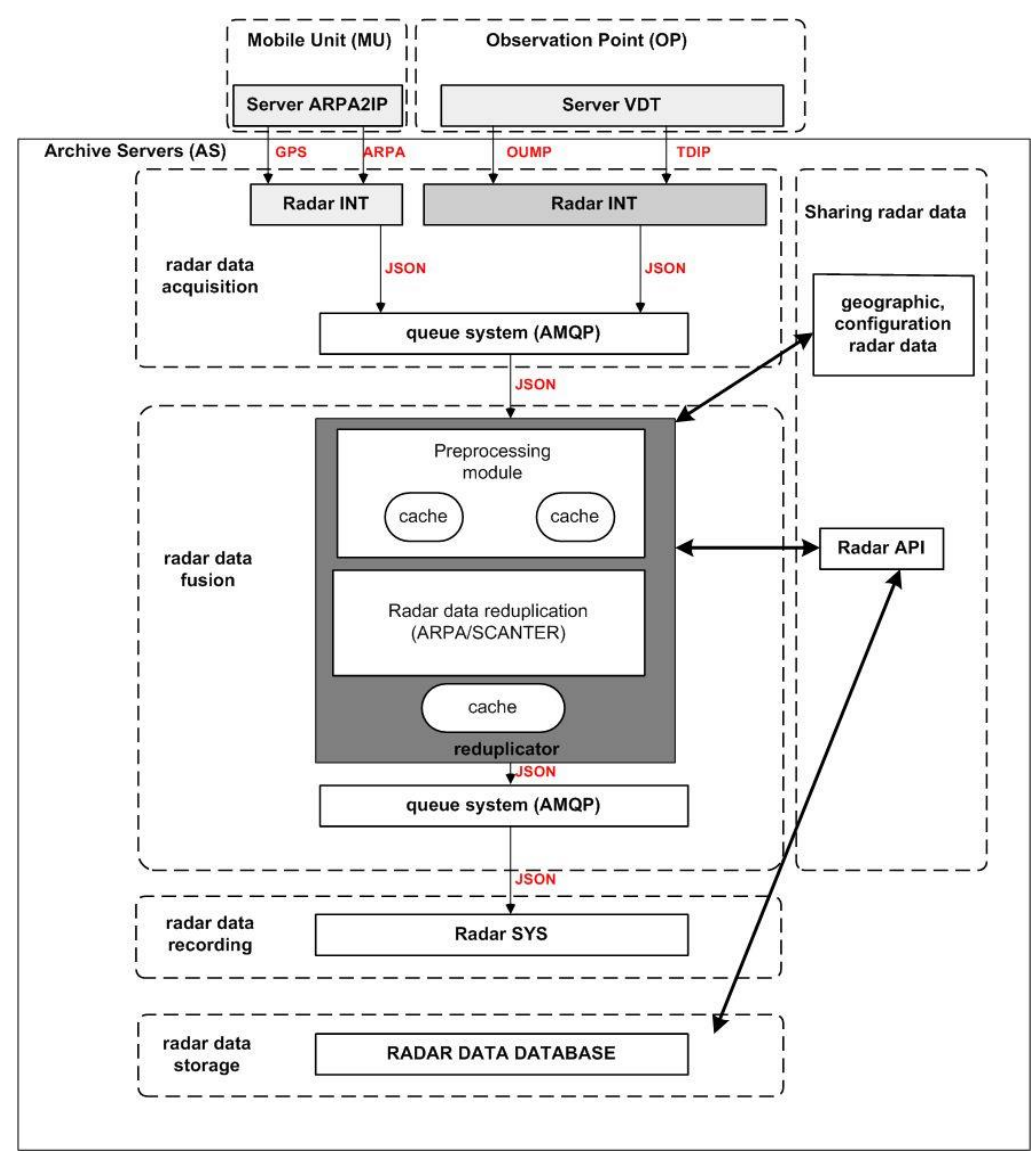

Fig. 3. Block diagram of the STRADAR system responsible for acquiring and reduplication radar data 
In preprocessing module packets' contents are verified and some of the crucial packets' fields are checked (i.e., geographical coordinates, UTC of data, etc). In the case of irregularities of this type of data at the initial stage of reduplication, these packages are rejected, and the information about irregularities may be additionally archived in AS.

In a typical case, radar antenna rotation period is about few seconds $(2,3$ seconds) and during single rotation of its antenna period, ARPA radar sends at first a series of TLL (Target Latitude and Longitude) radar packets which contain, among others, geographical coordinates and statuses of all targets which were tracked during this period. After that, it sends a series of TTM (Tracked Target Message) radar packets, containing other useful information about those targets [10].

Taking into consideration that visualization tools refresh situation on maps every 10 seconds, it is unnecessary to collect all radar data. For this reason some data rate limitations are introduced in the preprocessing module.

After rate limitation the TLL and TTM ARPA packets in preprocessing module are joined together for each tracked target and sent forward in a form of a single system packet containing all necessary data obtained from ARPA radar (header+ HighFrequencyArpaScanterData). HighFrequencyArpaScanterData for Scanter is also formed. For this operation each radar has its own cache for preprocessing. The packages receive local/global identifiers and as packets are stored in the cache, unless the state of acquisition of the target data has changed.

For combined TLL and TTM ARPA radar packages and SCANTER 2001 radar packages, radar data reduplication module assigns unique local/global identifiers within the entire system. Each URC device has a separate pool of these identifiers. Separate pools of identifiers also have SCANTER 2001 radars. Identifier pools are defined in the Archive Server SA from the web service level of REST architecture and made available to the radar data reduplication module through the Radar API module (fig. 1).

The reduplicator module eliminates packets of which copies with exactly the same content are stored in the cache including the radar data transferred to AS. Potential duplicate tracks are detected on the basis of tracks cache by comparing tracks which fulfill the following three conditions:

$$
\begin{aligned}
& \lambda_{\text {min }}-\lambda_{m} \leq \lambda \leq \lambda_{\text {max }}+\lambda_{m} ; \\
& \varphi_{\text {min }}-\varphi_{m} \leq \varphi \leq \varphi_{\text {max }}+\varphi_{m}
\end{aligned}
$$




$$
t_{\text {pom_min }}-t_{m} \leq t_{\text {pom }} \leq t_{\text {pom_ } \max }+t_{m}
$$

where:

$\lambda_{\min }, \lambda_{\max } \quad-$ minimal/maximal latitude coordinate;

$\varphi_{\min }, \varphi_{\max } \quad-$ minimal/maximal longitude coordinate;

$t_{\text {pom_min }}, t_{\text {pom_max }}-$ minimal/maximal timestamp coordinate;

$\lambda_{m}, \varphi_{m}, t_{m} \quad$ - assumed coordinate margins for latitude, longitude and timestamp.

The tracks extracted from cache need to be compared with the track with the best radar accuracy in order to find the best matching and make a proper decision to recognize these tracks as duplicate or not. The decision in reduplication process is made for different types of radars and priority radar data calculated based on radar accuracy are sent to radar data database in AS. Radar accuracy may be calculated based on STDERR or radar and object track position available in track message in SCANTER 2001 radar or target distance available in ARPA message or assumed in configuration process.

Compering the geographical coordinates in the same moments requires some kind of resampling method. For ARPA and SCANTER radars it is equal to the radar's antenna rotation period, i.e. according to specification rotation period for SCANTER 2001 is equal to $60 \mathrm{rpm}$. Such sampling rate is unnecessarily high because the state of map controls on mobile and stationary consoles is refreshed every 10 seconds. The proposed metric evaluating the (un)matching of both tracks are statistical metrics, namely mean error $(M E)$ and standard error of estimate (SEE) defined as:

$$
\begin{gathered}
M E_{\lambda, A}=\left(1 / N_{A}\right) \cdot \sum_{i=1}^{N_{A}} \lambda_{A, i}+\lambda_{B \rightarrow A, i} ; \\
S E E_{\lambda, A}=\sqrt{\sum_{i=1}^{N_{A}}\left(\lambda_{A, i}-\lambda_{B \rightarrow A, i}\right)^{2} /\left(N_{A}-1\right),}
\end{gathered}
$$

where:

$N_{A} \quad$ - number of sampling moments from $\operatorname{track} A$;

$\lambda_{A, i} \quad-$ longitude from track $A$ defined for $i$-th sampling moment from $\operatorname{track} A$;

$\lambda_{B \rightarrow A, i}$ - longitude from resampled track $B$ defined for $i$-th sampling moment from $\operatorname{track} A$.

Mean errors and standard error of estimate for $\varphi$ and $t_{\text {pom }}$ coordinates for track $A$ and $B$ are defined in analogous formulas.

3 (218) 2019 
The illustration of this problem is presented in [8], where the deduplication process is performed for AIS-based data and ARPA-based data in KONSOLA project system. The proposed algorithm is a simplified version of KONSOLA project system deduplication. The final metric evaluating of the (un)matching of both radars' tracks ( $A$ and $B$ ) is TV (track variance) defined as:

$$
T V=N_{A} \cdot T V_{A}+N_{B} \cdot T V_{B}
$$

where:

$$
\begin{gathered}
T V_{A}=0.5 \cdot\left(T V_{\lambda, A}+T V_{\varphi, A}\right) ; \\
T V_{B}=0.5 \cdot\left(T V_{\lambda, B}+T V_{\varphi, B}\right),
\end{gathered}
$$

where:

$$
\begin{aligned}
& T V_{\lambda, A}=\left(w_{M E} \cdot\left|M E_{\lambda, A}\right|+w_{S E E} \cdot\left|S E E_{\lambda, A}\right|\right) /\left(w_{M E}+w_{S E E}\right) ; \\
& T V_{\varphi, A}=\left(w_{M E} \cdot\left|M E_{\varphi, A}\right|+w_{S E E} \cdot\left|S E E_{\varphi, A}\right|\right) /\left(w_{M E}+w_{S E E}\right) ; \\
& T V_{\lambda, B}=\left(w_{M E} \cdot\left|M E_{\lambda, B}\right|+w_{S E E} \cdot\left|S E E_{\lambda, B}\right|\right) /\left(w_{M E}+w_{S E E}\right) ; \\
& T V_{\varphi, B}=\left(w_{M E} \cdot\left|M E_{\varphi, B}\right|+w_{S E E} \cdot\left|S E E_{\varphi, B}\right|\right) /\left(w_{M E}+w_{S E E}\right) .
\end{aligned}
$$

The $w_{M E}, w_{S E E}$ represent weight for mean error and standard error of estimate depending on radar accuracy. The track $A$ and $B$ are duplicated when $T V$ value will be below certain threshold level. The value of the threshold should be calculated in experimental way.

More detailed flow diagram of fusion process operations is presented in fig. 4 . In preprocessing module two processes are presented: ProcessPacket_ARPA for ARPA data operations and ProcessPacket_VDT for SCANTER data operations. The depicted PACKET_HFD_ARPA_SCANTER consists of header and HighFrequencyArpaScanterData. Fusion process manages temporary cache of radar objects with assigned packets forming their current tracks. New packets are assigned to track of the one of previous objects, to new object or to the object created based on the track detached from the one of previous objects. The track of the object to which packet has been assigned and tracks of its neighbors are next used for ME (4) and SEE (5) calculation. On this basis objects duplicates are detected and objects are fused. If a new objects results from fusion process then it is assigned an unique global identifier. 


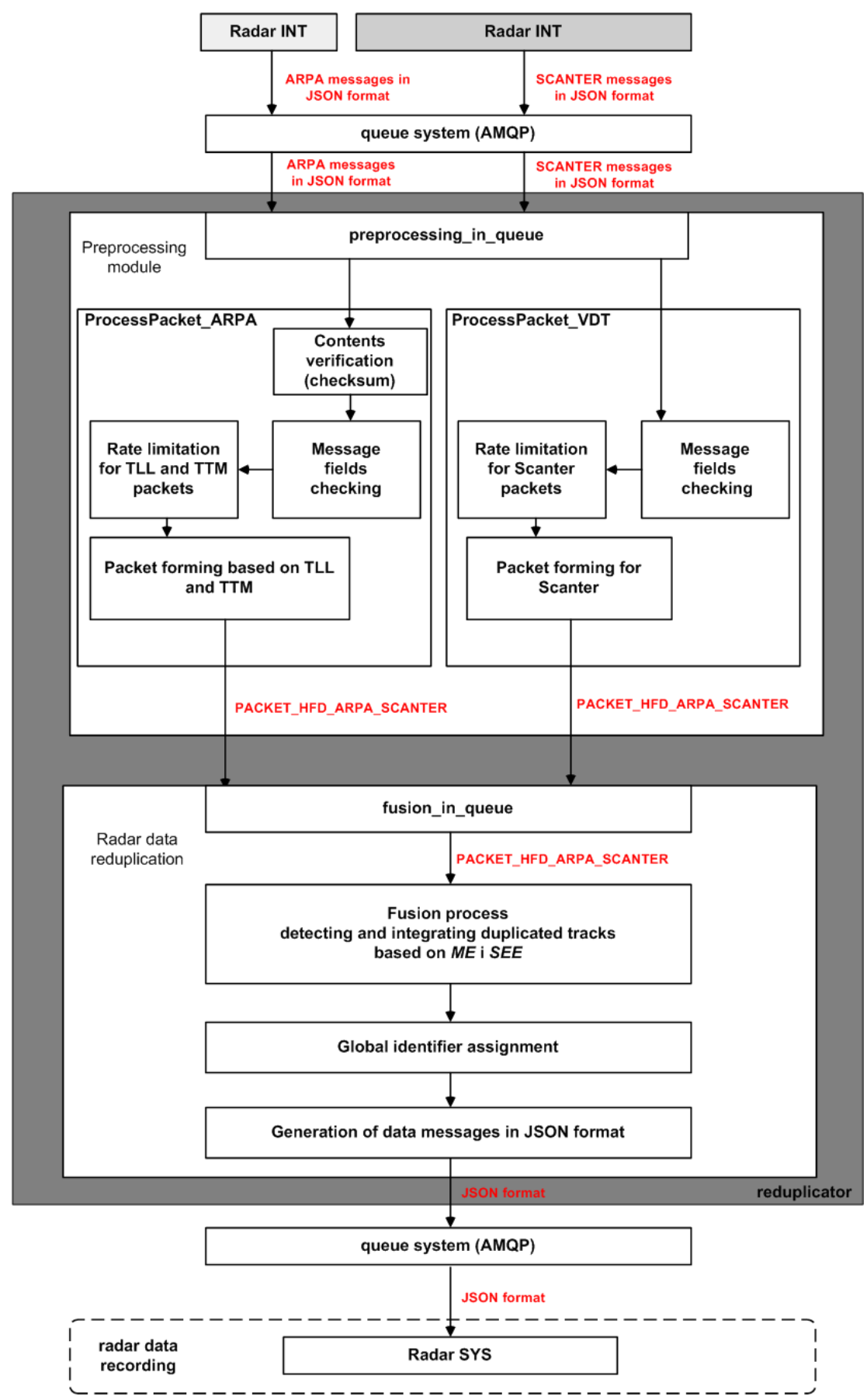

Fig. 4. Detailed flow diagram of the reduplication module responsible for acquisition and reduplication of radar data 


\section{CONCLUSIONS}

The paper describes the STRADAR system developed based on the KONSOLA project which was designed as an extension to the Automatic National System of Radar Control for Maritime Areas of Poland (ZSRN). In the paper the concept of the radar data gathering is described and the radar servers, Radar INT modules and reduplication module as well as the algorithm of radar data fusion (reduplication) is proposed. Future work will focus on implementation of proposed reduplication algorithm, as well as testing of the proposed solution in real operational conditions.

Due to the lack of direct access to SCANTER devices during the STRADAR project implementation, it is also necessary to develop a VDT server emulator which from the STRADAR perspective will provide all its necessary functionalities. The emulator will be equivalent to the actual server element providing test data based on recorded tracks from the actual VDT. This approach allows development and testing of the STRADAR system without the need to access real VDT devices, at the same time guaranteeing trouble-free cooperation with Terma's devices in the event of the cooperation with real BG's system.

\section{REFERENCES}

[1] Blok M., Czaplewski B., Kaczmarek S., Młynarczuk M., Narloch M., Sac M., Multimedia distributed system for visualization of ongoing and archival events for $B G$, The International Tech-Science Conference on 'Naval Technologies for Defence and Security', NATCon 2016, pp. 61-76.

[2] Blok M., Czaplewski B., Kaczmarek S., Litka J., Narloch M., Sac M., STRADAR - multimedia dispatcher and teleinformation system for the Border Guard, 'Scientific Journal of Polish Naval Academy', 2019, Vol. 216, No. 1, pp. 69-88, DOI: 10.2478/sjpna-2019-0006.

[3] Blok M., Kaczmarek S., Młynarczuk M., Narloch M., Mapserver — information flow management software for the border guard distributed data exchange system, 'Polish Maritime Research', 2016, Vol. 23, No. 3 (91), pp. 13-19.

[4] Czaplewski B., Blok M., Kaczmarek S., Narloch M., Performance Measurements and Optimization of Visualization of Routes Traveled in the Distributed Dispatcher and Teleinformation System for Visualization of Multimedia Data for the Border Guard, The European Navigation Conference (ENC 2019), 9-12 April, Warsaw 2019.

[5] Fiorini M., Maciejewski S., Lesson Learned During the Realization of the Automated Radar Control System for Polish Sea-waters (ZSRN), 'Marine Navigation and Safety of Sea Transportation: Advances in Marine Navigation', 2013, CRC Press, pp. 217-221. 
[6] Gałęziowski A., Zautomatyzowany system radarowego nadzoru polskich obszarów morskich, 'Przegląd Morski', 2005, No. 5, pp. 50-70 [National System of Radar Control for Maritime Areas of Poland - available in Polish].

[7] Hajduczenia J., Kaczmarek S., Sadowski J., Deduplication of tracked objects position data at single observation point of a Vessel Monitoring System, 'Scientific Journal of Polish Naval Academy', 2015, Vol. 201, No. 2, pp. 23-32, DOI: 10.5604/0860889X.1172069.

[8] Hajduczenia J., Kaczmarek S., Sadowski J., Deduplication of Position Data and Global Identification of Objects Tracked in Distributed Vessel Monitoring System, 'Telecommunication Review Telecommunication News', 2015, No.10, pp. 1563-1568.

[9] Lin B., Huang Ch.-H., Comparison Between ARPA Radar and AIS Characteristics for Vessel Traffic Services, 'Journal of Maritime Science and Technology', 2006, Vol. 14, No. 3, pp. 182-189.

[10] National Marine Electronics Association, NMEA 0183: Standard for interfacing marine electronic devices, version 3.01, 2002.

[11] Stateczny A., AIS and Radar Data Fusion for Maritime Navigation, 'Scientific Journals of the Maritime University of Szczecin', 2004, No. 2, pp. 329-336.

[12] Terma A/S, SCANTER Track Management Protocol, Document No. 303949 SI, Denmark, 2011, [online], http://www.umgdy.gov.pl/wp-content/uploads/2018/05/WI_SCANTER_TRACK.pdf [access 21.04.2019].

[13] Terma A/S, Scanter, Video Distribution and Tracking Unit, SCANTER 2001, Product Specification, Document No. 306872-DP, No. 070522, Denmark 2007.

[14] Terma A/S, SCANTER Own Unit Management Protocol, Product Specification, Document No. 304203-SI, Denmark, 2017.

[15] Wawruch R., New radar system along the Polish coast and inside Polish ports, 'Scientific Journals of the Maritime University of Szczecin', 2015, No. 44, pp.196-203.

\section{FUZJA DANYCH RADAROWYCH W SYSTEMIE STRADAR}

\section{STRESZCZENIE}

Głównym zadaniem polskiej Straży Granicznej jest ochrona granicy kraju, która wymaga wykorzystania multimedialnych systemów nadzoru umożliwiających automatyczne gromadzenie, przetwarzanie i udostępnianie różnego rodzaju danych. W artykule przedstawiono taki system opracowany dla Morskiego Oddziału Straży Granicznej w ramach projektu STRADAR oraz problem fuzji danych radarowych w tym systemie. System STRADAR, oprócz zapewnienia komunikacji pomiędzy elementami systemu, gromadzi i udostępniania dane z AIS, GPS i odbiorników radarowych: ARPA i SCANTER 2001. W artykule zaprezentowano koncepcję gromadzenia danych 
radarowych w systemie STRADAR, przedstawiono serwery radarowe, moduł radar INT i moduł reduplikacji oraz zaproponowano algorytm fuzji danych radarowych.

\section{Słowa kluczowe:}

fuzja danych, nawigacja, ARPA, SCANTER 2001, reduplikacja danych pozycyjnych.

Article history

Received: $\quad 05.06 .2019$

Reviewed: 12.07 .2019

Revised: $\quad 22.07 .2019$

Accepted: 23.07.2019 